\title{
Determination of the kinetic constants of the process of plasma gasification of coal-water fuel
}

\author{
Leonid Kholiavchenko ${ }^{1}$, Yevhen Pihida ${ }^{1}$, Serhii Demchenko ${ }^{1, *}$, and Serhii Davydov ${ }^{1}$ \\ ${ }^{1}$ Institute of Geotechnical Mechanics named by N. Poljakov of National Academy of Sciences of \\ Ukraine, 49005, Dnipro, Simferopolska Str., 2a, Ukraine
}

\begin{abstract}
The chemical kinetics of processes of thermal transformations of carbon-containing media was studied at high-temperature processing $(2000 \mathrm{~K} \leq T \leq 5000 \mathrm{~K})$ in the chamber of a plasma-jet reactor using water vapor as an oxidizer. The chemical reactions rate was calculated according to the method of determining the kinetic constants of the process of gasification of coal-water fuel. The influence of the temperature of the gaseous environment in the chamber on the time of complete carbon conversion of the fuel particles is established. An example of calculating the parameters of the gasification process of coke residue particles with a size of $(5-20) \cdot 10^{-5} \mathrm{~m}$ with an oxidizer excess coefficient $\alpha=0.45$ and fuel consumption $m_{f}=100 \mathrm{~kg} / \mathrm{hr}$ is given. The expediency of the process of vapor-plasma gasification at the temperature of gases in the reactor chamber up to $3000 \mathrm{~K}$ is shown.
\end{abstract}

\section{Formulation of the problem}

The significant attention has recently paid to the issue of processing solid fuel in order to obtain energy gaseous fuel, synthesis gas, which is necessary for the chemical and metallurgical industries in the production of synthetic liquid fuels and reducing media.

Coal is the most promising raw material for energy and chemical products. Therefore, there is always an increasing interest in the development of new processing conversions using new technologies.

Gasification of pulverized fuel or coal-water fuel with water vapor heated to high temperatures $(T \geq 2000 \mathrm{~K})$ in a plasma torch or plasma arc reactor $[1,2,3]-$ is the one of the possible methods of processing with the introduction of heat into the reduction zone from an external source

The degree of carbon processing, its productivity and energy intensity are the main parameters of the gasification process. Their high value can be reached by selecting the stoichiometric ratio of the initial components and optimizing the residence time of the reactive coal particles in the reaction zone, which is used as the basis for calculating the reactor parameters. Therefore, there is a need to study the sequential processes of thermal transformations of fuel in time in the reaction chamber, that is, the kinetics of chemical and

${ }^{*}$ Corresponding author: demchikigtm@gmail.com 
physicochemical processes occurring during the plasma-chemical transformations of complex organic substances. These processes include: spraying fuel; evaporation of water drops; heating of steam and coal particles before the output and ignition of volatile substances; the burning of volatile substances around the particle, contributing to the rapid increase of the particle temperature; gasification of coke residue, consisting of carbon and ash. Of course, these processes have different speed, duration and degree of influence on the gasification process depending on the specific conditions.

\section{Analysis of the recent research}

Some processes (atomization of fuel in the reactor chamber, evaporation of water droplets depending on their size, emission and combustion of volatile substances, heating of water vapor and coke particles in the reactor) were studied at a gas temperature in the reaction chamber up to $2000 \mathrm{~K}$, and their results are presented in work [4].

Chemical kinetics takes into account the time factor, that is, the rates of chemical reactions depending on temperature, pressure, mixture composition, state of aggregation, external energy sources and the presence of catalysts are considered. It is necessary to clarify the mechanism of the course of each chemical reaction by studying the factors that have influence on the speed of the overall process and its individual steps. Therefore, the study of the kinetics of reactions is usually associated with the rates of a number of proceeding reactions. The dependence of the rate of chemical reactions on temperature, applicable to both homogeneous reactions and reactions proceeding under the influence of irradiation, or on surfaces, is determined by the Arrhenius equation [5].

It is known that the rate of chemical reactions significantly increase at high temperatures in the reaction chamber. This circumstance necessitates the choice of the optimal residence time of the reacted coal particles in the reaction zone of the reactor. The deviation of the residence time from the optimal value during the gasification of the fuel leads to a change in the composition and yield of the target product. In addition, this factor significantly affects the geometric parameters (capacity) of the reaction chamber of the reactor. Therefore, in order to avoid overheating of the gaseous phase and the mineral part, as a gasification product, it is necessary to remove the high-temperature heating zone in a timely manner, especially if it exceeds the temperature of total carbon conversion $\left(T_{c}=1800-2000 \mathrm{~K}\right)[2]$.

The aim of this work is to study the chemical kinetics of the processes of thermal transformations of coal with different physicochemical properties in a high-temperature vapor-plasma flow $(2000 \mathrm{~K} \leq T \leq 5000 \mathrm{~K})$.

\section{Presentation of the main material}

When carbon is gasified in a vapor-plasma stream with a temperature of 2000-5000 K, heterogeneous reactions of carbon with water vapor and carbon dioxide are carried out, as well as a homogeneous reversible reaction of carbon monoxide with water vapor 1. $\mathrm{C}+\mathrm{H}_{2} \mathrm{O}=\mathrm{CO}+\mathrm{H}_{2} ; 2 . \mathrm{C}+2 \mathrm{H}_{2} \mathrm{O}=\mathrm{CO}_{2}+2 \mathrm{H}_{2} ; 3 . \mathrm{C}+\mathrm{CO}_{2}=2 \mathrm{CO} ; 4 . \mathrm{CO}+\mathrm{H}_{2} \mathrm{O}=\mathrm{CO}_{2}+\mathrm{H}_{2}$. It is assumed that the thermophysical characteristics and particle size remain constant during the heating time. The temperature of the heat carrier gas in the course of the reactor is assumed to be average at the stage of heating the particles. If the particle size, pressure and temperature conditions of the process, as well as the composition of the medium in which gasification takes place are known, then kinetic constants and mass transfer conditions are determined on the basis of these initial data.

The calculation of the gasification time of the coke residue can be carried out, provided 
that the area of conversion of the fuel particle is determined.

It is necessary to determine the reaction rate constant, the activation energy of the reaction $\mathrm{C}+\mathrm{O}_{2}=\mathrm{CO}_{2}$ for the fuel of this type, the mass transfer coefficient, the coefficient of mutual diffusion of substances. The activation energy of the reaction $\mathrm{C}+\mathrm{O}_{2}=\mathrm{CO}_{2}$ for cokes of solid fuels of different types and also the ratio between the activation energies of various reactions, are given in [6]. The following ratios of the activation energies of various reactions can be taken from the analysis of numerous experimental data: $E_{\mathrm{C}+\mathrm{H}_{2} \mathrm{O}} / E_{\mathrm{C}+\mathrm{O}_{2} \rightarrow \mathrm{CO}_{2}}=1.6 ; E_{\mathrm{C}+\mathrm{CO}_{2}} / E_{\mathrm{C}+\mathrm{O}_{2} \rightarrow \mathrm{CO}_{2}}=2.2$.

The reaction rate constant, which is determined by the Arrhenius ratio is one of the important parameters of the kinetics of the gasification process

$$
k_{i}=k_{0 i} e^{-E_{i} / R T_{g}},
$$

where $k_{i}$ is the rate constant of the $i$-th reaction, $\mathrm{m} / \mathrm{s} ; k_{0 i}$ - preexponential factor, $\mathrm{m} / \mathrm{s}$; $E$ - activation energy, $\mathrm{kJ} / \mathrm{kmol} ; R=8.314 \mathrm{~kJ} /(\mathrm{kmol} \cdot \mathrm{K})$ - universal gas constant; $T_{g}$ - gas temperature, $\mathrm{K}$.

The connection of the activation energy with the pre-exponential factor in the Arrhenius dependence has the following form

$$
\lg k_{0 i}=0.2 \cdot 10^{-4} E_{i}+2 .
$$

When the material exchange coefficient $\alpha_{\mathrm{d}}$ is determined, it is necessary to first find the speed of the particles hovering in the flow. For small particles (for example, $d_{p}=5 \cdot 10^{-5} \mathrm{~m}$ ), the small soaring rate, we can assume $\mathrm{Nu}_{\mathrm{d}}=2$. The coefficient of material exchange is determined by the equation

$$
\alpha_{d}=N u_{d} \cdot D / d_{p},
$$

where $\mathrm{Nu}_{\mathrm{d}}$ is the Nusselt diffusion criterion; $D$ - coefficient of mutual diffusion of substances, $\mathrm{m}^{2} / \mathrm{s} ; d_{p}$ - particle diameter of coal, $\mathrm{m}$.

The calculation of diffusion in multicomponent gas mixtures is complicated. In problems of combustion, it is permissible to use the quasi-binary model of diffusion, contrasting the component under consideration (we note its index 1) with the mixture of the remaining components as a unified gas. Approximate coefficient $D_{1 \mathrm{n}}$ can be determined from the relationship [6]

$$
D_{1 n}=\frac{1-x_{1}}{x_{2} / D_{12}+x_{3} / D_{13}+x_{4} / D_{14}+\ldots},
$$

where $x_{1}=p_{1} / P_{g}, x_{2}=p_{2} / P_{g}, x_{3}=p_{3} / P_{g}$ and so on - the molar fractions of the components in the gas mixture; $D_{12}, D_{13}, D_{14}$ and so on - coefficients of mutual diffusion of component 1 in a mixture with component 2 , component 3 and so on, $\mathrm{m}^{2} / \mathrm{s} ; p_{1}, p_{2}, p_{3}$ and so on - are the partial pressures of the components in the gas mixture, $\mathrm{Pa} ; P_{g}$ - gas pressure in the reactor chamber, $\mathrm{Pa}$. Here, the indices with $p$ denote the components: $\mathrm{O}_{2}-1 ; \mathrm{CO}_{2}-2$; $\mathrm{CO}-3 ; \mathrm{H}_{2}-4 ; \mathrm{H}_{2} \mathrm{O}-5$.

To calculate the mutual diffusion coefficient, the power dependence is used

$$
D_{12}=D_{012}\left(\frac{T_{c}}{T_{0}}\right)^{1.75} \cdot \frac{p_{0}}{P_{g}} .
$$


The mutual diffusion coefficients $D_{012}$ for some pairs of gases under normal conditions $\left(P_{0}=1.01 \cdot 10^{5} \mathrm{~Pa}, T_{0}=273 \mathrm{~K}\right)$ are given in [5]. When gasifying high-moisture fuels, such as peat, brown coal, wood, water coal, the analysis of the oxidation process is much more complicated in compare with the oxidation of relatively dry fuels. Most researchers consider the gasification of natural fuels as carbon conversion of coke residue. The rate of gasification of carbon particles of coke is determined by the formula [6]

$$
G_{c}=\frac{\alpha_{d}}{R \cdot T_{g}} \cdot\left[\frac{N_{3}}{1+N_{3}} p_{2}+\frac{N_{1}}{1+N_{1}}\left(p_{1}+0.5 p_{5}\right)\right],
$$

where $N_{i}=\frac{k_{i}}{\alpha_{d}}$ - is a dimensionless complex; $G_{c}$ - carbon gasification rate, $\mathrm{kmol} /\left(\mathrm{m}^{2} \cdot \mathrm{s}\right)$. The index at $N$ is the number of the $i$-th reaction. The region of carbon particle conversion is determined by the following condition: when $\alpha_{d}>k$ is the kinetic region; and when $\alpha_{\mathrm{d}}<<k$ - the diffusion area of gasification.

Now you can proceed to the calculation of the gasification time of the coke residue, using the formula for determining the $G_{c}$ in the corresponding gasification area.

After determining the parameter $G_{c}$ for these conditions, the gasification time of the coke residue particle can be calculated by the formula [6]

$$
\tau=\frac{\rho_{p} \cdot d_{p}}{2 M_{c} \cdot G_{c}}
$$

where $\rho_{p}$ - particle density, $\mathrm{kg} / \mathrm{m}^{3} ; M_{c}=12 \mathrm{~kg} / \mathrm{kmol}$ - molecular weight of carbon.

This method of determining the kinetic constants of the process of gasification of coalwater fuel was used in calculating the conversion time of particles of coke residue in the plasma-jet reactor chamber. It was shown in [7] that the conversion of carbon contained in coke takes $90 \%$ of the total conversion time of a solid fuel particle. The remaining $10 \%$ of the total conversion time is the release and burnout of volatile substances.

\section{Results and discussion}

In the present work, the calculation was carried out for the following initial data: oxidizer water vapor; fuel - particles of coke residue; oxidizer excess ratio $\alpha=0.45$; fuel consumption $m_{f}=100 \mathrm{~kg} / \mathrm{hr}$; oxidizer consumption $m_{o}=90 \mathrm{~kg} / \mathrm{hr}$; gas temperature in the chamber $T_{g}=2000-5000 \mathrm{~K}$; gas pressure in the chamber $P_{g}=1.1 \cdot 10^{5} \mathrm{~Pa}$; particle diameter of coke residue $d_{p}=(5-20) \cdot 10^{-5} \mathrm{~m}$; particle density $\rho_{p}=1600 \mathrm{~kg} / \mathrm{m}^{3}$. The fuel supply to the reactor chamber was carried out using a carrier gas (superheated steam), which accounted for $20 \%$ of the total amount of oxidizer. The remaining $80 \%$ of the total consumption is water that is contained in the fuel (for example, coal-water fuel). Then after dissociation of superheated steam in the reactor chamber, the components of the gas mixture will be presented by the oxygen, hydrogen and water vapor. In molar fractions, the components of the gas mixture in the reactor chamber have the following meanings $X_{\mathrm{H}_{2} \mathrm{O}}=0.801$; $X_{\mathrm{O}_{2}}=0.066 ; X_{\mathrm{H}_{2}}=0.133$. The partial pressures of the components in the chamber are $P_{\mathrm{H}_{2} \mathrm{O}}=88.11 \mathrm{kPa} ; P_{\mathrm{O}_{2}}=7.26 \mathrm{kPa} ; P_{\mathrm{H}_{2}}=14.63 \mathrm{kPa}$.

Since the composition of the gas mixture in the reactor chamber before the start of the reaction is missing a component of $\mathrm{CO}_{2}$, that is, $p_{2}=0$, the expression (6) can be written as 


$$
G_{c}=\frac{\alpha_{d}}{R \cdot T_{g}} \cdot\left[\frac{N_{1}}{1+N_{1}}\left(p_{1}+0.5 p_{5}\right)\right] .
$$

The analysis of the calculation results, which are shown in Figure 1, shows that the kinetic characteristics of the gasification process of the hydrocarbon fuel change significantly with increasing gas temperature in the reactor chamber. The nature of the curves is justified by the properties of the function $e^{E_{i} / R T_{g}}=k_{i} / k_{0}$, which determines the temperature dependence of the chemical reaction. When $T_{c}=0$, we have $e^{E_{i} / R T_{g}}=0$. With increasing temperature, the exponent increases sharply, the derivative is positive on the temperature. At high temperatures $(T \geq 3000 \mathrm{~K})$, the derivative decreases and the exponent asymptotically approaches unity. At some intermediate temperature, the curve has an inflection point. The temperature $T_{k}$, which is responsible for the inflection curve, can be determined by the dependence [6]

$$
T_{k}=\frac{E_{i}}{2 R}
$$

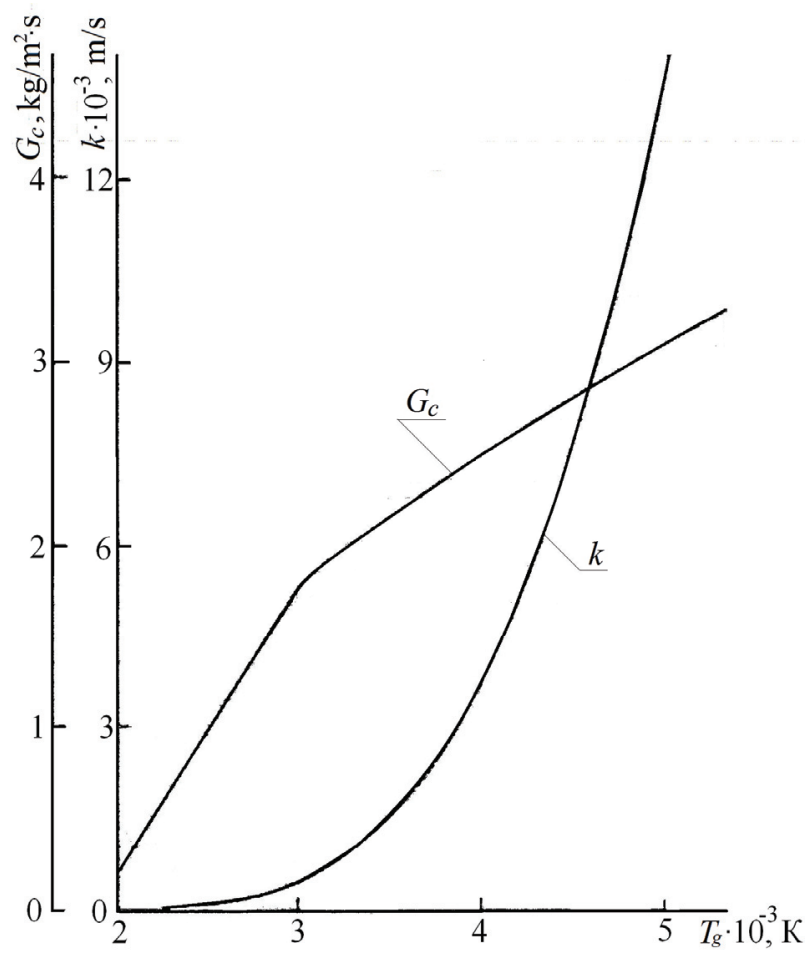

Fig. 1. Dependence of the parameters of the kinetics of the process of coal gasification on the gas temperature in the reactor chamber.

At temperatures lower than $T_{k}$, the reaction rate increases very strongly with temperature. So, with the gas temperature increasing from 2000 to $3000 \mathrm{~K}$, the reaction rate constant $\mathrm{C}+\mathrm{H}_{2} \mathrm{O}=\mathrm{CO}+\mathrm{H}_{2}$ increased by $385 \mathrm{~m} / \mathrm{s}$, and in the temperature interval from 3000 to $5000 \mathrm{~K}$ an intensive growth of the chemical reaction rate is observed at $13600 \mathrm{~m} / \mathrm{s}$.

The nature of the dependence of the rate of carbon conversion $G_{c}$ on the temperature of the gases in the reactor chamber is determined by the parameters of the kinetics: diffusion 
and the rate constant of the chemical reaction. In the temperature range from 2000 to $3000 \mathrm{~K}$, an intensive increase in the rate of carbon conversion in a linear dependence is observed, which slows down with a further increase in temperature in the chamber to $5000 \mathrm{~K}$.

A change in the gas temperature and, as a consequence, the rate constants of chemical reactions significantly affects on the coke particle gasification time. The calculation by equation (7) showed that increasing the temperature of the gas in the reactor chamber from 2000 to $5000 \mathrm{~K}$ leads to decrease the coke particles time gasification of the size $d_{p}=(5-20) \cdot 10^{-5} \mathrm{~m}$. When the gas temperature in the chamber changes from 2000 to $3000 \mathrm{~K}$, the coke particles time gasification decreases accordingly 8 to 3 times. With increasing gas temperature in the reactor chamber $\left(T_{g}>3000 \mathrm{~K}\right)$, a low rate of gasification time reduction is observed. This is due to abrupt changes in the parameters of the kinetics at high gas temperatures in the chamber, which leads to a change in the value of the conversion rate of carbon to a coke particle. Consequently, the temperature regime $T_{g}=$ $3000 \mathrm{~K}$ in the reactor chamber during the gasification of fuel is preferable. Since it provides a sharp reduction in the time of gasification of coke particles of size $d_{h}=(5-20) \cdot 10^{-5} \mathrm{~m}$.

Thus, we can conclude: in the practical implementation of the process of gasification of carbon-containing fuel in order to increase its productivity it is necessary to carry out the process at temperatures $T_{g} \leq 3000 \mathrm{~K}$. At the same time, it is necessary to take into account the fact that the process of complete conversion of carbon of a fuel particle is completed at its heating temperature up to $1900 \mathrm{~K}$. This will prevent overheating of the fuel, that is, to obtain high-quality synthesis gas, determine the optimal heating time and geometrical parameters of the reaction chamber, as well as the place where the processed fuel is introduced into it.

\section{References}

1. Romaev, V.I. (1977). Preparation of the reducing coal gas fuel interaction with water vapor in the plasma jet. Tezisy Doklady II Vsesojuznogo soveshhanija po plazmohimicheskoj tehnologii i apparatostroeniju, 1, 80-85

2. Bulat, A.F., Kholyavchenko, L.T. (2008). Fiziko-tehnicheskie osnovy processov konversii $i$ gazifikacii uglerodosoderzhashhih mineral'nyh sred pri vozdejstvii vysokotemperaturnyh koncentrirovannyh potokov jenergi: otchet o NIR [Physical and technical bases of conversion and gasification processes carbonaceous mineral medium under the influence of high concentrated energy flows: Report of research], IGTM of the NAS of Ukraine, Dnipropetrovsk, Ukraine

3. Mineev, S.P. (2009). Svojstva gazonasyshhennogo uglja. Dnipropetrovsk: NGU

4. Kholiavchenko, L.T., Pigida, E.Ju., Davydov, S.L. (2013). Nekotorye aspekty kinetiki processa plazmo-strujnoj pererabotki vodougol'nyh dispersnyh system, Materialy XXIII Mezhdunarodnoj nauchnoj shkoly imeni Hristianovicha, 285 - 288

5. Longvell, P. (1961). Gorenie zhidkih topliv. Processy gorenija. Moskva: Fizmatgiz

6. Pomerancev, V.V. (1986). Osnovy prakticheskoj teorii gorenija. Leningrad: Energoatomizdat

7. Pomerancev, V.V. (1983). Sbornik zadach po teorii gorenija. Leningrad: Energoatomizdat 